\title{
Bestiario fronterizo: chupacabras, zonkeys, vampiros y las representaciones de los miedos del norte
}

Border Bestiaries: Chupacabras, Zonkeys and the Representations of the Fears of the North

\section{Martín Camps ${ }^{1}$}

University of the Pacific, California, Estados Unidos

mcamps@pacific.edu

\section{RESUMEN}

El ensayo estudia los bestiarios políticos que se han generado en la frontera entre México y Estados Unidos, como el chupacabras, los vampiros fronterizos, el zonkey show y la bestia o el tren que acarrea migrantes al norte. Estas bestias de la modernidad ilustran los miedos del norte impuestos a los habitantes del sur como una estrategia fantasmática para demonizarlos y alejarlos del centro global y los cotos del poder económico. Sin embargo, en estos monstruos puede residir también la fuerza para ejercer el espanto con profesionalismo y para reconfigurar las representaciones simbólicas de lo fronterizo como la zona ignota de lo prohibido e ilegal.

\section{PALABRAS CLAVE}

Bestiarios, frontera, México, crónicas

\section{ABSTRACT}

This paper studies the political bestiaries that have been generated on the border between Mexico and the United States, such as the chupacabras, border vampires, the zonkey show and «the beast» or the train that transports migrants to the north. These beasts of modernity illustrate the fears that northerners have placed on the inhabitants of the south as a phantasmatic strategy to demonize them and keep them away from global center and

\footnotetext{
1 Martín Camps ha publicado cinco libros de poesía y artículos académicos sobre la frontera entre México y Estados Unidos. Actualmente es profesor asociado de Literatura Latinoamericana en la University of the Pacific en Stockton, California, donde también es director del Programa de Estudios Latinoamericanos.
} 
preserve the economic power. However, in these monsters there can also reside the strength to exercise fright professionally and to reconfigure symbolic representations of the border as the unknown area of the forbidden and illegal.

\section{KEY WORDS}

Bestiaries, border, Mexico, chronicles

En El libro de los seres imaginarios, Jorge Luis Borges nos dice en su prólogo: «Invitamos al eventual lector de Colombia o del Paraguay a que nos remita los nombres, la fidedigna descripción y los hábitos más conspicuos de los monstruos locales» (p. 7). Este artículo responde a la llamada de Borges y añade algunas entradas a su peculiar enciclopedia de extraños engendros de que es capaz el arca la fantasía humana. Borges describe monstruos que se refugian tras las letras, como arpías, el asno de tres patas, la banshee, el basilisco, los elfos y morlocks, que se esfuman si se pronuncian y solo aparecen cuando se ejerce el conjuro de la lectura. Al sur del río Bravo de la frontera mexicana, se encuentra un bestiario bizarro construido por los miedos del norte reflejados en el sur. Estos agentes de la «barbarie», que convenientemente siempre vienen de «abajo», deben mantenerse al margen del centro global, como lo llama Harm de Blij (1999), que intenta protegerse «higiénicamente» de los agentes contaminantes o aterrorizadores de la paz ficticia del primer mundo. La frontera simboliza una barricada de protección, una membrana o «frontera de cristal» (Fuentes, 1995) que mantiene a los indeseables al margen. A principios de siglo, en la frontera se «higienizaba» con gasolina a los mexicanos que cruzaban la línea política para prevenir de monstruos microscópicos (piojos) y que en una infeliz ocasión un grupo de mexicanos fue «accidentalmente» prendido en llamas². La paranoia fronteriza consiste en que todos los males vienen del sur. Actualmente se corrió el rumor de que grupos del Estado Islámico se encontraban en Ciudad Juárez, sin presentar ninguna evidencia y, como consecuencia, el control fronterizo se endureció afectando a los habitantes de la zona. A pesar de que ninguno de los extremistas responsables de los ataques en 2001 en Nueva York entraron por fronteras mexicanas, sino canadienses, la frontera entre México y Estados Unidos fue la que más se agudizó y los habitantes de las

2 No hay que olvidar que en la época de los linchamientos en Estados Unidos, muchos mexicanos fueron víctimas del odio racial. Ver el importante estudio de William D. Carrigan y Clive Webb (2013). Forgotten Dead: Mob Violence Against Mexicans in the United States 1848-1928. Oxford: Oxford University Press. 
fronteras tuvieron que sufrir las consecuencias de filas kilométricas para cruzar o ser escrutados como si en ellos residiera un terrorista potencial.

Ciudad Juárez es la entrada del tercer mundo, el rincón donde se acumulan los miedos y se construye lo latinoamericano conceptual o fantasmático que no se ajusta a la realidad. Slavoj Žižek (1999, p. 25), al hablar de lo fantasmático, dice: «[El] tercer mundo como el infierno en la Tierra, como un lugar desolado en el que solamente la caridad y la compasión -y no una actividad política - pueden aliviar el sufrimiento». La frontera, en su carácter fantasmático, ha sido definida como «laboratorio de la posmodernidad» (Canclini, 1990) donde se ensayan los proyectos económicos para implementar en América Latina. Recordemos, es en esta zona donde se alojan miles de maquiladoras extranjeras que se benefician de la mano de obra barata y la cercanía al coloso del norte.

En este trabajo analizaré cinco bestias de la frontera: el chupacabras, el zonkey, el donkey show, el vampiro fronterizo y el tren de migrantes conocido como la bestia. Me interesa hablar de las representaciones de los miedos proyectados hacia el sur y en las fronteras para hacer un microinventario de los bestiarios fronterizos. Sabemos que fue en la época de la prohibición en Estados Unidos que se catapultó la economía de las fronteras y se fraguó su identidad como lugares de permisividad y donde todo era adquirible a un determinado precio: drogas, sexo, alcohol, una triada que sentenció Manu Chau en su canción: «Welcome to Tijuana: tequila, sexo y marihuana». La cercanía con Estados Unidos y la disponibilidad de lo prohibido contribuyó a crear la «leyenda negra» de la frontera. Dice Edgar Cota-Torres (pp. 54-55) a este respecto: «Border cities have created a modified and exotic Mexico that exploits an indigenous Mexican past absent to this area, while constructing an image of its own out of its realities and necessities that complement those associated with la leyenda negra». Humberto Félix Berumen, en su libro Tijuana la horrible, desmenuza la historia y el mito de Tijuana en la literatura y en los medios de comunicación, así como la iconografía que situó en esta ciudad el centro del vicio y la corrupción.

Los bestiarios tuvieron su auge en la época de la conquista. María José Rodilla (2014, p. 195), en su artículo sobre los bestiarios del Nuevo Mundo, establece que en la imaginación de los conquistadores figuraba la búsqueda de lo maravilloso: «Querían encontrar seres imaginarios como amazonas y gigantes, sirenas y grifos; el padre Tello afirmaba que en Tlala había 27 gigantes con tres mujeres que para su dieta requerían de cuatro niños asados y una fanega de maíz diariamente». La rica imaginación medieval alimentada por historias de la Biblia y el desconocimiento científico de nuevas especies (por ejemplo, los manatíes, que fueron confundidos 
frecuentemente con sirenas) incitaba en su imaginación la aparición de figuras fantásticas en las zonas ignotas de los mapas del sur, que eran ilustradas con monstruos mitológicos. El Centauro del Norte: se le llamó así a Pancho Villa después de su incursión en el poblado de Columbus, donde se le representó en los periódicos de la época como una figura mitológica que invadía; por primera vez, aparecía un caudillo latinoamericano lacerando la paz norteamericana.

En el México contemporáneo, la guerra contra el narcotráfico desatada en 2007, durante el sexenio de Felipe Calderón, ayudó a incrementar la imagen monstruosa de la ciudad, monstruo que en su origen etimológico significa lo deforme, lo mal hecho, lo abyecto. Ciudad Juárez fue el centro que sufrió los estragos de un campo de batalla, donde murieron más de diez mil ciudadanos y otros tantos miles están desaparecidos. El escritor y periodista Sergio González Rodríguez $(2014$, p. 85) formula que México se convirtió en efecto en un "campo de guerra» donde los ciudadanos viven en la continua irrupción de la paz en un clima de «fricción y de niebla». Escribe: «Mientras que el campo de guerra lo permite, la persona es invisible; una vez que se vuelve visible y un objetivo, la persona entra en la anamorfosis, que tiene una cualidad adicional: expresa la desmesura. Frente a esta, la persona se ve y se siente indefensa. La desmesura o quiebre del orden convencional es la fábrica de los monstruos y las monstruosidades». Rodríguez utiliza el concepto de «anamorfosis» o distorsión de una imagen mediante un procedimiento óptico que provoca un efecto de perspectiva y desproporción. Los criminales incorporan lo monstruoso para deformar la realidad, el uso de lo simbólico, como las decapitaciones, el desollamiento, desmembramiento, la desmesura en sus artefactos; por ejemplo, los vehículos todoterreno modificados con todo tipo de armamento y defensa para proyectar una imagen monstruosa e inspirar miedo en sus enemigos y desestabilizar la sociedad o, como lo llaman en su argot violento, «calentar una plaza».

Un concepto adicional que puede clarificar los procesos que se fraguan en la frontera es el término que propone Sayak Valencia (2012, p. 89) como el capitalismo gore; esto es, el capitalismo salvaje al extremo que se regodea en la violencia que ejerce el neoliberalismo mexicano:

De esta manera, el capitalismo gore podría ser entendido como una lucha intercontinental de (pos)colonialismo distópico extremo; recolonizado a través de los deseos de hiperconsumo implantados por el neoliberalismo exacerbado y obediencia acrítica ante el orden hegemónico masculinista para lograr autoafirmación y empoderamiento.

En este sentido, la frontera mexicana está en la vanguardia del capitalismo patibulario y representa el espejo empañado donde se reflejan 
los miedos mitológicos hacia la «barbarie». Roland Barthes escribe que el mito «constituye un sistema de comunicación, un mensaje» (1999, p. 199) y un «mito madura porque se extiende [...] en lo que los lingüistas llamarían las isoglosas de un mito, las líneas que definen el espacio social en que es hablado» $(1999$, p. 246). La frontera es un sitio perfecto para la implantación de mitos por ser zonas movedizas donde confluyen ondas culturales que están en continúa negociación y choque. El mito también es «un lenguaje que no quiere morir: arranca los sentidos de los que se alimenta una supervivencia insidiosa, degradada, provoca en ellos una prórroga artificial en la que se instala cómodamente, los convierte en cadáveres parlantes» (1999, p. 227).

El hambre semiológica del mito se extiende en el cadáver parlante por antonomasia, el zombi, el habitante mitológico de nuestra contemporaneidad, que es tal vez la metáfora más oportuna para la frontera. Escribe Fernández Gonzalo (2011, p. 194): «El zombi, como metáfora, nos permite acceder al mundo que nos rodea desde una visión compleja de la cultura propia». En el contexto de la crítica poscolonial de Achille Mbembe, su concepto de «necropolítica» (alimentado por la noción de biopoder foucaltiano) exhibe las formas de dominación del mundo del sur (o el tercer mundo) que han sido marginalizados y cuyas vidas no cotizan en el mercado mundial del necropoder que impone su soberanía en decidir quién merece vivir o morir. Escribe Mbembe (2011, p. 75):

[L]as armas se despliegan con el objetivo de una destrucción máxima de las personas y de la creación de mundos de muerte, formas únicas y nuevas de existencia social en las que numerosas poblaciones se ven sometidas a condiciones de existencia que les confieren el estatus de muertos-vivientes.

Hagamos entonces un recuento por algunos animales mitológicos fronterizos, animales que son exabruptos de la zoología política y la desproporción de la realidad monstruosa con la que se representa a los países allende el río Grande.

\section{El Chupacabras del fin de siglo}

En su crónica milenarista «[Aquí...] todos somos El Chupacabras», del escritor veracruzano Luis Arturo Ramos, incluida en su libro Crónicas desde el país vecino (1998), el Chupacabras fue la señal ominosa que se esperaba como parte de los augurios del fin del mundo. El Chupacabras era una quimera vampiresca (el «Bigfoot» mexicano, si se quiere, aunque el Sasquatch no es agresivo — criatura del norte, después de todo- y su enigma reside en su elusividad) que se creía chupaba a las cabras y fue la mascota que los mexicanos inventaron para entrar en el siglo XXI. Dice 
Ramos (1998, p. 106): «A semejanza del sida, el Chupacabras fue descubierto en el tercer mundo; como la marihuana y la migración, también procede del sur». Esta entidad ficticia, expone irónicamente Ramos, es para los norteamericanos la encarnación de lo extravagante, «otro nombre posible para los Josés Martínez o Juanes González que acechan los alrededores» (1998, p. 107). El Chupacabras simbolizó los monstruos inconscientes del fin de siglo, dado que «la necesidad de creer va aparejada a la necesidad de inventar» (1998, p. 108).

El Chupacabras, compara Ramos, es la versión latinoamericana de E. T., el Extraterrestre. Sin embargo, este ser representa para los norteamericanos la encarnación del sur, del desorden, la anticultura. Dice Ramos (1998, p. 109):

Si el Extraterrestre cura, educa, ilumina y juega con los inocentes, el Chupacabras enferma, contamina y mata. El Extraterrestre procede del norte, del cielo, a bordo de una nave iluminada y lleva un mensaje de paz y progreso; el Chupacabras personifica el sur, el miedo, la sucia oscuridad de los corrales y se le nombra en español: el idioma de la barbarie.

El Chupacabras representa para los norteamericanos el miedo a los otros y justifica el cierre de tres mil kilómetros de frontera no solo con México, sino con Latinoamérica. El Chupacabras es «la inconsciente encarnación de la xenofobia; para nosotros aparece como una extravagante ansiedad de afirmación y supervivencia» (Ramos, 1998, p. 110). El escritor propone que si no quisimos ser el Subcomandante Marcos (líder del Ejército Zapatista de Liberación Nacional), seamos entonces todos el Chupacabras, seamos el «espanto del primer mundo» (Ramos, 1998, p. 110). Esta crónica, además de su refinado humor negro, es una actualización milenarista de «Nuestra América» de José Martí, ya que si hemos de jugar el papel de villanos, dice Ramos, al menos debemos asumir nuestro rol representándolo profesionalmente.

\section{El vampiro fronterizo: el temor homoerótico}

El origen de esta bestia se remite a los chistes, que como se sabe son indicadores culturales significativos y según Freud el chiste es «la contribución hecha a lo cómico por el inconsciente» (citado por Žižek, 1999, p. 174). Monsiváis decía que para entender una cultura hay que entender de qué se ríen. El chiste se refiere a un vampiro que viola extranjeros en la frontera. Hay varias versiones, pues, como relato que pertenece a la narrativa oral, se metamorfosea según el contador, se modifica y se añaden detalles, pero la anécdota central es la de un «gringo» que regresa a Estados Unidos después de pasearse en la frontera y el guardia fronterizo le 
advierte la presencia de un vampiro violador que se aparece después de la medianoche. $Y$ justo cuando cruza el norteamericano, aparece el vampiro sobre el cofre del auto. El gringo regresa al lado americano y el guardia le enseña un conjuro para repeler el ataque que hay que repetir tres veces, y reza así: «Vampiro fronterizo, que por las noches andarás, donde quiera que andes, hagas lo que hagas, mis nachas [trasero] no las tendrás». El gringo, confiado, cruza la frontera de nuevo y en efecto se aparece el vampiro. El gringo repite el conjuro las tres veces indicadas, pero el vampiro se acerca a la puerta del conductor y dice extrañado: «What?». El vampiro no hablaba español. El chiste habla sobre el bilingüismo fronterizo, el gringo debió haber repetido el conjuro en español y en inglés, para cerciorarse. El chiste esconde el miedo a cruzar la frontera, el miedo a la violación masculina, a ser devorado por una entidad maliciosa que acecha en la zona liminar entre los dos países y cuyas víctimas se pierden en la traducción o el bilingüismo.

Si la leyenda del donkey show atrae el morbo de algunos visitantes de las fronteras como el culmen de lo bizarro y la zoofilia, el vampiro fronterizo añade la violación por un vampiro que no chupa la sangre, pero que penetra a sus víctimas en una suerte de desvirgamiento internacional que tal vez pretende ser una justicia poética a los norteamericanos que buscan sexo en las zonas de tolerancia de las fronteras. Los vampiros se han situado también en el imaginario fronterizo, por ejemplo en la película From Dusk Till Dawn (1996), de Quentin Tarantino y Robert Rodriguez — que en 2014 se ha hecho serie en la televisión por cable-, donde se juega con la idea de un antro o prostíbulo llamado Titty Twister que captura a viajeros norteamericanos para chuparles la sangre. En la escena final, vemos que el bar está situado sobre una pirámide precolombina, en una hipótesis fantástica del pasado soterrado y misterioso que para los cineastas se traduce en vampiros y en el desfiladero se pueden ver montañas de autos y los tráileres de sus víctimas. Tanto en el chiste de «el vampiro fronterizo» como en From Dusk Till Dawn, la frontera es la zona de permisividad y desfogue, así como sitio liminar entre los vivos y los muertos. El vampiro puede representar también un miedo venero (al sida o las enfermedades de transmisión sexual), un miedo a ser contaminado por medio de mordida (también en caló significa el «cohecho» o ejercicio de la corrupción de los policías) o infección de otro vampiro.

\section{Zonkey y el donkey show, los monstruos híbridos}

El zonkey o la mezcla de cebra y burro aparece en las calles de Tijuana para atraer a los turistas, como figura de ornato o de utilería para la fotografía del recuerdo, donde se puede aparecer montado en el animal 
con un sombrero mexicano. Sin embargo, el animal tijuanense no es un cebroide, sino un burro blanco con las rayas pintadas. Es un fraude, una mentira que es parte del bestiario fronterizo, su forzada hibridez, su antifaz para fingir una cruza con cebra, cuando en realidad es un simple burro pintado. Pero en las fronteras, en Tijuana, lo que importa es la simulación de lo mexicano; que el turista se lleve una buena fotografía y que se cree la ilusión de México. «The zonkey masks the donkey, in much the same way that the trinkets and colorful objects representing Mexico mask the border» (Cota Torres, 2007, p. 55). El zonkey encaja en la taxonomía de la zoología política; por su hibridez y simulación, es un ente fronterizo que vive de su antifaz y ha profesionalizado su identidad para encontrar su pastura. En las fronteras es redituable actuar lo mexicano o performancear la identidad; esto es, convertirse en un mexicano profesional.

Por su parte, el donkey show pertenece a una estirpe desviada, el animal que es forzado a sostener una relación con una mujer. El acto de zoofilia se encuentra en el más soterrado círculo de la noche fronteriza, cuando se llega a presenciar ese show que nadie realmente sabe si existe o es solo un mito, de pronto, hasta una promesa al final de la noche de farra. En su crónica «La Juárez» — que forma parte del libro Road to Ciudad Juárez (Moreno, 2014, p. 189)—, Jorge Humberto Chávez Ramírez se adentra en la noche juarense, con la ayuda de un taxista, para encontrar definitivamente el obsceno «show» y escribe:

Un taxista nos subió a su lapidado Crown Victoria y dio vueltas por callejones del centro hasta que fue imposible saber adónde diablos habíamos ido a parar. En una estrecha calle, el taxista llegó a un portón negro, pitó y segundos después abrieron la puerta. Entramos al patio de una vecindad jodida y pintada de verde. [...]

-Tenemos donkey show, pero ya no hay burro. Van a ver a dos muchachas con una verga grandota de plástico — nos dijo la encargada del negocio.

El autor concluye más adelante: «Pero el punto es que en Juárez, si no es la violencia, es una crisis, una devaluación, y entre el bagaje perdido de nuestra ciudad también está el espectáculo de zoofilia que los gringos asocian con la decadente frontera mexicana» (Moreno, 2014, p. 189). En efecto, el donkey show es la degradación animalesca de la frontera, un acto contranatural que puede significar el estigma de «tierra de nadie» fronterizo, lugar donde prolifera la corrupción y la ignominia tiene precio en los rincones de la noche juarense. Rodilla León nos recuerda que Ordóñez, en su misoginia medieval, encuentra que los monstruos demonológicos por lo general son seres mixtos de mujer y animal, como las esfinges, harpías, gorgonas y sirenas, «que además de símbolos maléficos son también 
encarnaciones de la lujuria en la Edad Media» (2014, p. 203). El donkey show es la construcción de un monstruo fronterizo que también encarna la lujuria y proyecta la misoginia actual como lo fue en el medievo.

\section{La bestia de hierro de la modernidad}

"La bestia» o el tren de la muerte, que atraviesa México y lleva en su lomo a miles de migrantes de Centroamérica, es tal vez una de las bestias más dantescas del repertorio fronterizo. Como dice uno de los migrantes del documental La bestia (2010), «este tren es un demonio, es traicionero, ha cobrado miles de vidas». En el latín, con bestia se denominaba a los animales que combatían en el circo, que puede ser el animal de carga, pero también un ser fantástico que devora lentamente a sus pasajeros. «La bestia» se puede clasificar entre los cancerberos, la bestia de tres cabezas que cuida el inframundo y no permite que los muertos salgan ni que los vivos entren. México es el cruce más difícil del viaje de los migrantes. Desde el río Suchiate, que separa México de Guatemala, hasta el río Bravo, en Chihuahua. Dice uno de los entrevistados en el documental: «Como dice Dante, hay que poner en la frontera de México: aquí empieza el infierno». La frontera de Estados Unidos se ha mudado hacia el sur, a Chiapas. Los migrantes abordan el tren en la ciudad de Arriaga, después de caminar por diez días por las vías antiguas del tren; la mayoría llegan descalzos, con los zapatos reventados. Desde allí deben montarse al tren y arriesgarse a ser arrestados por la migración mexicana o ser secuestrados por los narcotraficantes para buscar un rescate de sus familiares en Estados Unidos. El padre Alejandro Solalinde, coordinador del albergue Hermanos en el Camino, es uno de los pocos que se dedica a defender a los viajeros (de los agentes de migración mexicana y de los narcotraficantes) y habla de la indefensión en la que se encuentran estos migrantes, sobre todo las mujeres que son violadas en los furgones vacíos. "La bestia» es la creación de la modernidad, el caballo de acero que construyó Porfirio Díaz para modernizar México (y que también fue el instrumento idóneo para derrocarlo al convertirse en el modo de transporte de las tropas revolucionarias), y todavía tiene un papel primordial, pero ahora en el panorama de la globalización, del desplazamiento de los excluidos, de los que están destinados a emigrar para encontrar condiciones de vida mejores. El tren corta brazos a los que se duermen, decapita a los que se distraen y no se agachan cuando se cruzan túneles, corta las piernas de quien da un mal paso, arrolla a los niños que caen de los brazos de sus madres. Los fierros retorcidos de la modernidad que acarrean los materiales de la modernización también llevan el trabajo humano en la forma de adultos, niños y hasta bebés. Todo México se ha convertido en un territorio fronterizo, en un río Grande/río Bravo que debe detener a los migrantes, porque en México, 
a diferencia de otros países, la presencia de la migración se encuentra en todo el país, para hacerle el trabajo sucio a Estados Unidos. El tren es una sierpe de metal creada por los mismos que la denuncian y la temen. La bestia arroja a miles de niños a la frontera, 66 mil menores, algunos niños de ocho y nueve años, como los que recoge el documental Which Way Home (2009), que se pierden en el entramado de vías. La desesperación es tan grande que los padres dejan que sus hijos hagan el temible viaje. El tren es el demoledor de los sueños, el cercenador y el vehículo de transporte de los migrantes. Como en la reciente película mexicana La jaula de oro (2013), es un viaje donde las mujeres deben esconder su género vendándose los pechos para burlar a los violadores y a los narcotraficantes que las secuestran para explotarlas en el mercado de trata de blancas. El gobierno mexicano ha ordenado que se aumente la velocidad del tren para que los migrantes no puedan treparse al bólido, lo que significa un mayor riesgo y número de personas mutiladas en las vías. Además, se aumentan las cuotas para pagar a esa otra entidad carroñera que lucra con la desesperación de las personas y que recibe el nombre de coyote.

Sin duda, hay otras criaturas que se han aparecido de manera extraña o que han tenido historias bizarras que circulan en el imaginario fronterizo (por ejemplo, la historia de un león que se ahorcó en el zoológico de Ciudad Juárez; algunos teorizan humorísticamente porque se dio cuenta de la ciudad en que estaba). También existe el caso de un hombre que fue sorprendido por las autoridades con una tortuga de concha blanda que se salió del río Bravo y que está en peligro de extinción. El hombre fue encarcelado por nueve años de prisión por ser acusado de poner en riesgo la fauna ecológica del río. En la Universidad Autónoma de Ciudad Juárez también hubo el caso de un toro que se escapó de la Facultad de Veterinaria y tuvo en jaque a estudiantes y oficiales. Asimismo, animales exóticos aparecen de pronto por las calles: camellos, jirafas y leones que se escapan de los bestiales privados de capos de la droga, durante las detenciones recientes de narcotraficantes en la ciudad, animales salvajes que algunas veces son usados como tácticas intimidatorias para sus enemigos, tal vez algo aprendido de películas como Scarface. El narcotráfico ha tenido también consecuencias en los animales, por ejemplo con los perros cocainómanos que registran los cruces fronterizos, perros que pueden detectar la droga mejor que otros mecanismos, pero que lo hacen porque son furiosamente farmacodependientes. Hace unos años, con motivo de la amenaza del virus $\mathrm{H} 1 \mathrm{~N} 1$, aunque el riesgo de contaminación estaba en el Distrito Federal, las fronteras se cerraron y los trabajadores fronterizos fueron obligados a ir a sus casas durante varios días por temor al contagio. Recientemente, con la expansión del ébola y el primer caso registrado en 
Chihuahua por un viajero que provino de Dallas, en México se empezó a discutir la posibilidad irónica de controlar la frontera de Estados Unidos.

En estos cinco monstruos: el chupacabras, el zonkey y el donkey show, el vampiro fronterizo y la bestia, la genealogía de los monstruos políticos que se reflejan en el sur son ominosos, se construyen en el espejo turbio del miedo; el sur representa una amenaza, un peligro que debe ser detenido. Sin embargo, estos monstruos debajo de la cama de la geopolítica mundial tienen como propósito vender la idea de la barbarie latinoamericana, de crear una leyenda negra para consolidar una bipolarización de los incluidos y excluidos, de los que amasan los recursos mundiales y los que deben arriesgar sus vidas para escapar de la violencia y la pobreza. La frontera no es, por lo tanto, un cristal que permitiría visualizar al otro, sino más bien una pantalla donde se proyecta el miedo al otro, al que viene del sur para propagar enfermedades y amenazar la economía o el bienestar de los «suburbios» planetarios del norte. Muchas veces, el que manufactura estos monstruos viene del norte, el que provoca inestabilidad en los países del sur o echa andar la maquinaria de la muerte en forma de monstruos más limpios; por ejemplo, en forma de drones, pájaros voladores y bellos artefactos que llevan en sus vientres más horrores y destrucción que el simple y hambriento chupacabras. 


\section{REFERENCIAS BIBLIOGRÁFICAS}

Barthes, R. (1999). Mitologías. México D. F.: Siglo XXI Editores.

Borges, J. L. (2007). El libro de los seres imaginarios. Madrid: Alianza Editorial. Berumen, H. F. (2011). Tijuana la horrible: Entre la historia y el mito. Tijuana: Colegio de la Frontera Norte.

Camissa, R. (Director). (2009). Which Way. Estados Unidos: HBO Documentary. Cota-Torres, E. (2007). Dispelling the Border Myth: Zonkey Writers and the Black Legend. En Manzanas, A. M. (Ed.). Border Transits: Literature and Culture Across the Line (pp. 53-60). Ámsterdam: Rodopi.

Blij, H. de (2009). The Power of Place: Geography, Destiny and Globalization's Rough Landscape. Oxford: Oxford University Press.

Fernández Gonzalo, J. (2011). Filosofía zombi. Barcelona: Anagrama.

Fuentes, C. (1995). La frontera de cristal: una novela en nueve cuentos. México D. F.: Alfaguara.

García Canclini, N. (1989). Culturas híbridas. Estrategias para entrar y salir de la modernidad. México D. F.: Grijalbo.

González Rodríguez, S. (2014). Campo de guerra. Barcelona: Anagrama.

Mbembe, A. (2011). Necropolítica (seguido de) Sobre el gobierno privado e indirecto. Madrid: Melusina.

Moreno Montero, A. (Ed.). (2014). Road to Ciudad Juárez. Crónicas y relatos de frontera. México D. F.: Samsara.

Quemada Diez, D. (Director). (2013). La jaula de oro. México: Animal de Luz Films.

Ramos, L. A. (1998). Crónicas desde el país vecino. México D. F.: Universidad Autónoma de México.

Rodilla León, M. J. (2014). Bestiarios del Nuevo Mundo: maravillas de Dios o engendros del Demonio. RILCE: Revista de Filología Hispánica, 23(1), pp. 195-205.

Ultreras, P. (Director y Actor) (2010). La bestia. México, Estados Unidos, El Salvador y Guatemala.

Tarantino, Q. (Director) (1996). From Dusk Till Dawn. Estados Unidos: Dimension Films y A Band Apart.

Valencia, S. (2012). Capitalismo gore y necropolítica en México contemporáneo. Relaciones internacionales, GERI-UAM, (19), pp. 83-102.

Žižek, S. (1999). El acoso de las fantasías. México D. F.: Siglo XXI Editores. 